\title{
Application of Analytic Hierarchy Process in fuzzy logic-based meteorological support system of unmanned aerial vehicles ${ }^{1}$
}

\author{
TUBA Zoltán, VIDNYÁNSZKY Zoltán, BOTTYÁN Zsolt, WANTUCH Ferenc, \\ HADOBÁCS Katalin²
}

\begin{abstract}
This article aims to present the potential connection point of the analytic hierarchy process (AHP) and the fuzzy logic-based analog forecasting method. When we try to find the most similar situations with an analog forecasting system, we can be confronted with the problem of the different importance of different meteorological parameters. We can solve this problem by weighting the individual variables. We applied AHP to determine the correct weights. The preliminary results of a case study show the effectiveness of this application in analog forecasting support sys- tems for unmanned aerial vehicles (UAVs).
\end{abstract}

\section{Introduction}

The operational use of UAVs has had a significant growth in the past decades around the world. (Gertler, 2012) The number of registered unmanned systems has increased from 544 to 1424 between 2005 and 2011. (Skrzypietz, 2012) Nowadays the military applications are more common, namely the UAVs are able to complete a military mission without risk of loss of life and with low costs. With the help of modern remote sensing devices they are exceed-ingly applicable for completing surveillance, reconnaissance and intelligence missions, too. Nowadays the scope of civilian applications is significantly widening. The most important non-military fields are disaster management, protection of critical infrastructure and scien- tific research, etc. (Skrzypietz, 2012) In most cases the weather has greater impact on UAVs, than on aircraft replaced during implementation. It primarily depends on the different char- acteristics of UAVs (e.g. size, weight, etc.) and the devices applied. (Joint Air Power Com-

1 Research supported by the European Social Fund (TÁMOP-4.2.1.B-11/2/KMR-2011-0001, Research of Critical Infrastructure Defense). The project was realized through the assistance of the European Union, with the co-financing of the European Social Fund

2 Tuba Z. is with the Faculty of Military Sciences and Officer Training, National University of Public Service,

Budapest, H-1581, Hungary (phone: 00367032766001; fax: 003656505129 (e-mail:

tubazoltan.met@gmail.com).

Vidnyánszky Z. is with the Institute of Mathematics, Eötvös Loránd University, Budapest, H-1117 Hungary

(e-mail: vidnyanszkyz@gmail.com).

Bottyán Z. is with the Faculty of Military Sciences and Officer Training, National University of Public

Service, Budapest, H-1581, Hungary (e-mail: bottyan.zsolt@uni-nke.hu).

Wantuch F. is with the Aviation Authority, National Transport Authority, Vecsés, H-2220 Hungary e-mail: wantuch.f@gmail.com).

Hadobács K. is with the Geoinformation Service, Hungarian Defence Forces, Budapest, H-1524, Hungary

(e-mail: katalin.hadobacs@gmail.com). 
petence Center, 2010) (Bottyán, 2012: 418-422) It draws attention to the importance of the accuracy of ultra-short term weather forecasts, which are used in the final stage of planning and during the mission execution. Statistics based analog methods can give assistance to make more accurate these types of forecasts. (Riordan, Hansen, 2002: 139-146) At present in Hungary there is no operational weather support for UAVs at all. That is the reason why our goal is to develop a fuzzy logic-based analog forecasting subsystem as a part of a complex meteorological support system for UAVs. This article aims to show an application of the an- alytic hierarchy process, which can activate and refine our system under development. First of all we present the fuzzy logic-based forecasting system, after that we show the analytic hierarchy process and their possible connection point in the field of analog forecasting. At the end we demonstrate the application of AHP through a case study.

\section{Fuzzy Logic-Based Analog Forecasting System}

The basic principle of analog forecasting is to find similar weather situations in past and present actual conditions and rank them according to the degree of their similarity in the interest of giving relevant information for weather forecasts. For a theoretical basis of an operational fuzzy logic-based analog forecasting system, the reader can refer to Hansen et al (2007: 1319-1330). We based our statistical approaches on their results. First of all we set up a database for Hungarian military airports, which is based on routine aviation weather reports (METARs). (Bottyán et al., 2012: 11-18) The applied fuzzy logic-based algorithm measures the similarity of the elements of this database. The fuzzy sets - which are composed for de- scribing the degree of similarity between two variables - used in this process are determined by operational meteorologists, which is a common method in the development of fuzzy sys- tems. (Meyer et al., 2002: 105123) Fig. 1 shows an example of the fuzzy sets.

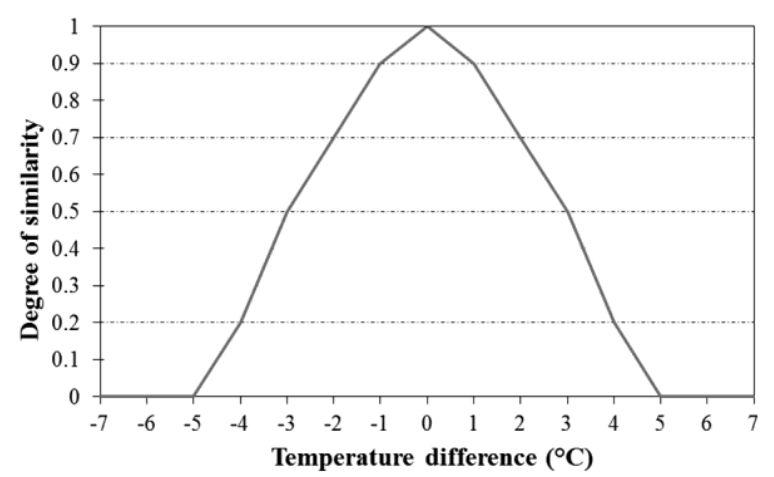

Figure 1. Example of a fuzzy set: degree of similarity in the function of temperature difference

When the temperature difference equals zero the similarity value is the highest (1). If the mentioned difference reaches $5^{\circ} \mathrm{C}$, then similarity will be zero. The intermediate values $(0.9$,

$0.7,0.5$, and 0.2 ) connected to the expressions of similarity (very similar, between very and quite similar, quite similar, slightly similar) respectively. The individual parameter values of 
a situation are examined one by one and the overall similarity of a situation is arrived at from averaging or the minimum of the similarity of the elements. The two approaches of determin- ing the overall similarity work parallel in this process until we can choose the better one us- ing the forecast verification results. After finding the most similar situations we can compose a prediction from the consecutive observations of the chosen situations with an appropriate method which is under construction. Obviously, the initial values of a given meteorological parameter from the most similar cases have a determinative role in the forecast process. The higher the difference between initial values, the higher the risk of an inaccurate forecast. As it mentioned earlier, the main goal is to improve the meteorological support of UAV-flight missions. As in every aviation task, the accurate cloud ceiling and the horizontal visibility forecast have an important role in the success of mission execution. In addition, the accurate prediction of these meteorological elements is one of the greatest forecasting challenges for aviation forecasters.

The lines above lead to our assumption: we can improve the accuracy of the forecast of individual elements by using appropriate weights highlighting the importance of them during the fuzzy logic based forecasting process. The application of suitable weights gives more similar initial values for the parameters selected as more important. There is another way to take better account of ceiling and visibility: the appropriate designation of fuzzy sets. But this method is very complicated, because the expert judgments are hardly applicable in an indi- rect way. Normally the experts determine for example how the different horizontal visibility values are similar to each other to get the fuzzy set. But in this case they have to define the potential modification of the fuzzy set in order to increase or decrease the importance of a meteorological parameter because of its perfect prediction.

In our opinion weighting of the variables is significantly simpler and at the same time a better solution for emphasizing importance of meteorological elements in this question. That is why we chose the first method which will be described in details later.

\section{Analytic Hierarchy Process}

The Analytic Hierarchy Process was introduced by Saaty (1977: 234-281) and motivated by the psychology of decisions. The AHP is basically a technique for ranking regarding various criteria when initially we have subjective comparisons. This method is widely used in deci- sion making, especially to solve complex problems such as the selection of the appropriate candidate for a job, allocation of strategic resources etc. One of the strengths of the AHP is that it assigns numbers to each possible choice, making the further calculations easier. It turned out that it can be applied in our situation for weighting the importance of the meteo- rological parameters based on forecasting experts' opinion.

Let us formulate the original problem. We are given $n$ objects (in our case the different meteorological parameters) and our aim is to find weights $\mathrm{w}_{\mathrm{i}}$ for $\mathrm{i}=1, \ldots, \mathrm{n}$ such that the weight $\mathrm{w}_{\mathrm{i}}$ refers to the importance of the $\mathrm{i}^{\text {th }}$ object. Initially we only have an estimation on the ratio of the importance of the $\mathrm{i}^{\text {th }}$ and the $\mathrm{j}^{\text {th }}$ object for each pair $\mathrm{i}, \mathrm{j}$. Let us denote these estimates by $a_{i j}$ for $i, j=1, \ldots, n$. Then of course we require $a_{i j}=\frac{1}{a_{j i}}$.

Note that these might be inconsistent, i. e. $\mathrm{a}_{\mathrm{ij}} \mathrm{a}_{\mathrm{jk}}=\mathrm{a}_{\mathrm{ik}}$ not necessarily holds. For example we can start with the assumption that the $1^{\text {st }}$ object is 2 times more important than the $2^{\text {nd }}$ one, 
the $2^{\text {nd }}$ is also 2 times more important than the $3^{\text {rd }}$, but the $1^{\text {st }}$ is only 3 times more important than the $3^{\text {rd }}$. In such a situation we cannot expect that the weights will perfectly reflect the ratios. Thus, our goal is to find $\mathrm{w}_{\mathrm{i}}{ }^{\prime} \mathrm{s}$ such that the difference between $\mathrm{a}_{\mathrm{ij}}$ and $\frac{\mathrm{w}_{\mathrm{i}}}{\mathrm{w}_{\mathrm{j}}}$ is as small as
possible.

Let us denote by A the $\mathrm{n} \times \mathrm{n}$ matrix of the ratios. It is easy to see that if the given ratios are consistent then the desired vector of weights $\mathrm{W}=(\mathrm{w}, \ldots, \mathrm{W})$ is an eigenvector of the matrix $\mathrm{A}_{1}$

with eigenvalue $n$, or in other words $A w=n w$ and in such a case $n$ is the maximal eigenvalue.

Surprisingly the converse also holds, Saaty proved that for any matrix of the type described above the matrix is consistent if and only if $\lambda_{\max }=\mathrm{n}$ where $\lambda_{\max }$ denotes the maximal eigenvalue of $A$. Moreover, he proved that even in the case of inconsistency the best choice for the weight vector is the eigenvector belonging to $\lambda_{\max }$ in the sense, that it minimizes a certain function of the differences between $\mathrm{a}_{\mathrm{ij}}$ and $\mathrm{w}_{\mathrm{i}}$ (for the detailed proof see Saaty (1977: 234-281).

$\mathrm{w}_{\mathrm{j}}$

To determine the eigervector we usgd the standard power iteration method. Saaty advised measuring the consistency of the given matrix with $\lambda_{\max }-\mathrm{n}$ which $\lambda_{\max }-\mathrm{n}$ turned out to be a

reasonable estimate. $\quad-\mathrm{n}-1-\mathrm{n}-1$

Using the above statements the AHP process goes as follows:

- assignation of the estimated ratios $\mathrm{a}_{\mathrm{ij}}$ for $\mathrm{i}, \mathrm{j}=1, \ldots, \mathrm{n}$ yielding the matrix $\mathrm{A}$;

- calculate the eigenvector $\mathrm{w}_{\max }$ of A belonging to the maximal eigenvalue $\lambda_{\text {max }}$ by iteration;

- norming $\mathrm{w}_{\max }$ gives the desired vector $\mathrm{w}=\left(\mathrm{w}_{\mathrm{p}}, \ldots, \mathrm{w}_{\mathrm{n}}\right)$ such that $\mathrm{w}_{\mathrm{i}}$ is the weight of the $\mathrm{i}^{\text {th }}$ object.

\section{Weighting of Meteorological Parameters}

As we have shown in the previous chapter the analytic hierarchy process is a method of multi-criteria decision making. To make a connection between AHP and the original problem to be solved it is necessary to model the problem as a hierarchy. In our case the goal of analog forecasting means decision making: to find the most similar situation in the database. So the alternatives are the single weather reports. Each of these routine observations contains the actual values of the different meteorological variables. In AHP there are criteria for evalu- ating alternatives. For criteria and subcriteria we used please refer to Fig 2. The number of the criteria and sub-criteria gives the difficulty of finding the best alternatives. Even in case of two criteria and two alternatives, the decision making can be very difficult if the different criteria prefer different alternatives. The meteorological problem to be solved has seven dif- ferent criteria and subcriteria, and more than 100000 different alternatives. Because of the large number of alternatives we do not apply the whole analytic hierarchy process for finding the most similar situations, but for this step we have the fuzzy logic-based algorithm which is described above. 


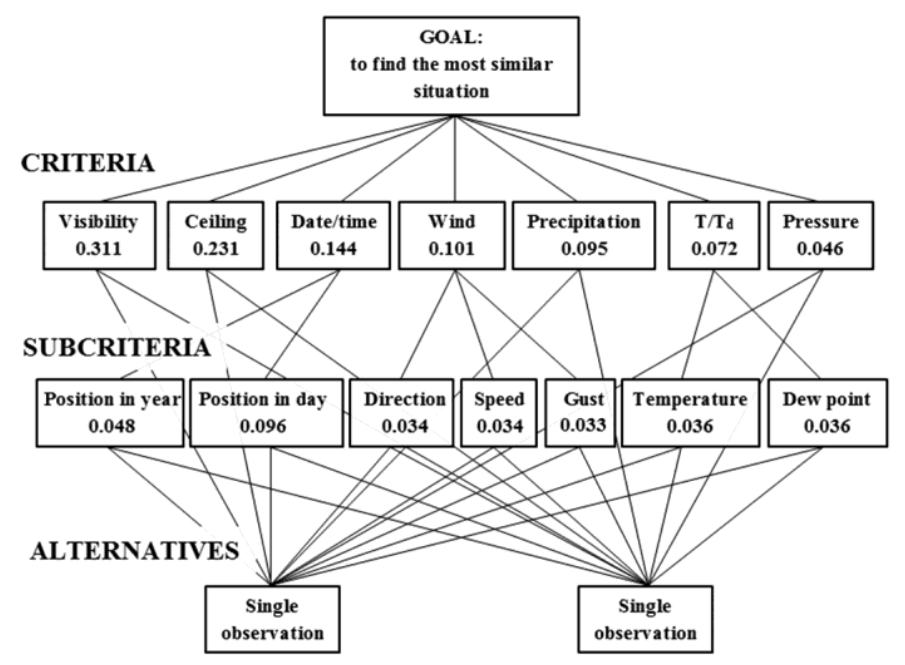

Figure 2. AHP hierarchy of the problem and the weights obtained

We used AHP only for weighting criteria which are meteorological and time parameters. Originally we have had eleven variables, which are now classified into seven criteria. Four of them are divided into sub-criteria because of the dependence and unimportance of variables. In the first step we collected the expert judgments of pairwise comparison of criteria based on a general definition (Table 1.). Some of the final results of pairwise comparison are shown in Table 2. These ratios give the elements of the matrix defined in the previous chapter. Then we determined the desired weights using the method described earlier. The received weights will be shown at the case study. Inconsistency is $2.5 \%$ which is less than the tolerable $10 \%$, so the results are significantly reliable.

Table 1. Domination, definition and mathematical background of pairwise comparison

\begin{tabular}{|l|l|c|}
\hline Domination & Definition & Math \\
\hline No & Equal & $1: 1$ \\
\hline Weak & Between equal/ slightly more & $1: 2$ \\
\hline Moderate & Slightly more & $1: 3$ \\
\hline Moderate plus & Between slightly more/more & $1: 4$ \\
\hline Strong & More & $1: 5$ \\
\hline Strong plus & Between more/much more & $1: 6$ \\
\hline Very strong & Much more & $1: 7$ \\
\hline Very strong plus & Between much more/ definitely much more & $1: 8$ \\
\hline Absolute & Definitely much more & $1: 9$ \\
\hline
\end{tabular}


Table 2. Some example of results of pairwise comparison

\begin{tabular}{|c|c|c|}
\hline Parameter to be compared & Applied ratio & Parameter to be compared \\
\hline Precipitation & $1: 1$ & Wind \\
\hline Date/Time & $2: 1$ & Wind \\
\hline Visibility & $5: 1$ & Pressure \\
\hline Visibility & $2: 1$ & Ceiling \\
\hline Date/Time & $1: 2$ & Ceiling \\
\hline$\ldots$ & $\ldots$ & $\ldots$ \\
\hline
\end{tabular}

\section{Case Study}

First of all we determined the appropriate initial values used at the case study. Our earlier conditional climatological analysis were able to help us to look for a situation in which we could find any height of ceiling at a given visibility value. The chosen ceiling category (amber line on Fig 3.) has a relative frequency maximum at $2000 \mathrm{~m}$ visibility. Additionally its value is similar to the relative frequencies of completely different ceiling categories. The appropriate selection of the rest of the examined parameters can maximize the number of similar situations differ significantly only in ceiling. We can represent the initial conditions with a fictional meteorological report: METAR LHSN 150745Z 23006KT 2000 BR BKN005

M00/M01 Q1017=. The meaning of this report is: the METAR was made on the 15th day of the month (in this case the month was January) at 07:45 UTC in Szolnok, Hungary. The wind is from $230^{\circ}$ and the wind speed is 6 knots. The horizontal visibility is $2000 \mathrm{~m}$ because of the mist and the cloud ceiling height is 500 feet. The temperature is $0^{\circ} \mathrm{C}$; the dew point temperature is $-1^{\circ} \mathrm{C}$. The sea level pressure is $1017 \mathrm{hPa}$.

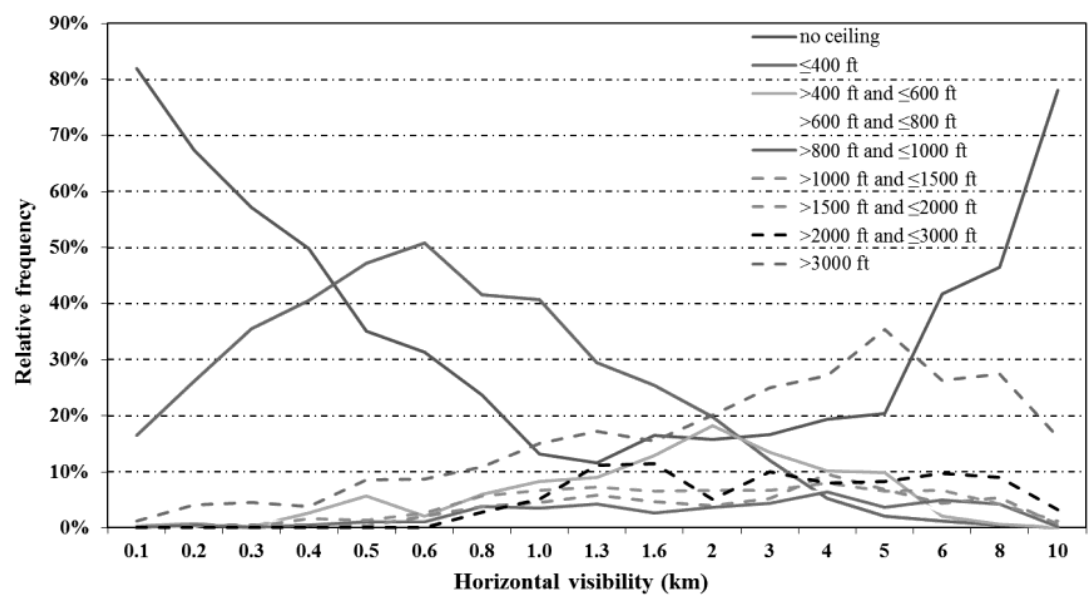

Figure 3. Changes of relative frequency of ceiling with horizontal visibility

We ran the similarity model two times: we used equal weights in case \#1 and the results of AHP pairwise comparison as optimized weights in case \#2 (Table 3.). 
TUBA et al: Application of Analytic Hierarchy Process in fuzzy logic-based meteorological support system...

Table 3. Applied weights in similarity model runs

\begin{tabular}{|r|c|c|}
\hline Criteria/Subcriteria & Applied weights in case \#1 & Applied weights in case \#2 \\
\hline Horizontal visibility & 1.0 & 0.311 \\
\hline Cloud ceiling & 1.0 & 0.231 \\
\hline Date/time & & \\
\hline \multicolumn{1}{|r|}{ position in year } & 1.0 & 0.048 \\
\hline position in day & 1.0 & 0.096 \\
\hline Wind gurection & 1.0 & \\
\hline gust & 1.0 & 0.034 \\
\hline Precipitation & 1.0 & 0.034 \\
\hline Temperature/Dew point & 1.0 & 0.033 \\
\hline temperature & & 0.095 \\
\hline dew point & 1.0 & \\
\hline Pressure & 1.0 & 0.036 \\
\hline
\end{tabular}

The similarity model runs gave significantly different results. As we mentioned earlier the applied weights have a key role, when we bring into focus some chosen meteorological parameters. That is the reason why we present and highlight the most similar situations in the view of the most important variables (Table 4.). In case \#2 all of the first ten individual visi- bility values and the mean ceiling are equal to initial values (2000 $\mathrm{m}$ visibility and $500 \mathrm{ft}$ ceil- ing) and the deviation is less than the smallest applied difference in meteorological reports.

Table 4. Results of the similarity model runs based on different weights

\begin{tabular}{|c|c|c|c|c|}
\hline \multirow{2}{*}{$\begin{array}{c}\text { Rank of the most } \\
\text { similar situations }\end{array}$} & \multicolumn{2}{|c|}{ Case \#1 } & \multicolumn{2}{c|}{ Case \#2 } \\
\cline { 2 - 5 } & visibility & ceiling & visibility & ceiling \\
\hline 1 & $2000 \mathrm{~m}$ & $5000 \mathrm{ft}$ & $2000 \mathrm{~m}$ & $500 \mathrm{ft}$ \\
\hline 2 & $3000 \mathrm{~m}$ & $5000 \mathrm{ft}$ & $2000 \mathrm{~m}$ & $500 \mathrm{ft}$ \\
\hline 3 & $3000 \mathrm{~m}$ & $400 \mathrm{ft}$ & $2000 \mathrm{~m}$ & $400 \mathrm{ft}$ \\
\hline 4 & $2000 \mathrm{~m}$ & $5000 \mathrm{ft}$ & $2000 \mathrm{~m}$ & $400 \mathrm{ft}$ \\
\hline 5 & $2500 \mathrm{~m}$ & $600 \mathrm{ft}$ & $2000 \mathrm{~m}$ & $600 \mathrm{ft}$ \\
\hline 6 & $1500 \mathrm{~m}$ & $400 \mathrm{ft}$ & $2000 \mathrm{~m}$ & $400 \mathrm{ft}$ \\
\hline 7 & $2500 \mathrm{~m}$ & $600 \mathrm{ft}$ & $2000 \mathrm{~m}$ & $500 \mathrm{ft}$ \\
\hline 8 & $2000 \mathrm{~m}$ & $700 \mathrm{ft}$ & $2000 \mathrm{~m}$ & $500 \mathrm{ft}$ \\
\hline 9 & $2500 \mathrm{~m}$ & $600 \mathrm{ft}$ & $2000 \mathrm{~m}$ & $600 \mathrm{ft}$ \\
\hline 10 & $3000 \mathrm{~m}$ & $500 \mathrm{ft}$ & $2000 \mathrm{~m}$ & $600 \mathrm{ft}$ \\
\hline Mean & $2400 \mathrm{~m}$ & $1880 \mathrm{ft}$ & $2000 \mathrm{~m}$ & $500 \mathrm{ft}$ \\
\hline deviation & $489.9 \mathrm{~m}$ & $2044.4 \mathrm{ft}$ & $0.0 \mathrm{~m}$ & $77.5 \mathrm{ft}$ \\
\hline
\end{tabular}


TUBA et al: Application of Analytic Hierarchy Process in fuzzy logic-based meteorological support system...

In case \#1 the results are unconvincing. The deviation is extremely high and three of the first four situations present a totally different synoptic situation in cloud conditions. This case study indicates the effectiveness of the optimized weights and foreshadows its usefulness in fuzzy logic-based analog forecasting systems.

\section{Conclusion}

The potential application of analytic hierarchy process in a fuzzy logic-based forecasting system has been described. The applied weighting method proved its efficiency in many different fields of life. The convincing preliminary results of the case study show the applica- bility of the procedure in the field of meteorology.

A probable continuation of this study is the extension of the case study as detailed verifi- cation of the analog forecasting method based on initial values of a similarity model.

A possible extension of this research appears promising. Applied weights adjusted to actual weather situations could improve the effectiveness of meteorological support of UAVs by the increasing accuracy of forecasts.

\section{References}

GERTLER, J. (2012): U.S. Unmanned Aerial Systems, Congressional Research Service, January 3

SKRZYPIETZ, T. (2012): Unmanned Aircraft Systems for Civilian Missions, BIGS Policy Paper No. 1, February 2012, http://www.microdrones.com/references/case-tudy/BIGS_PolicyPaper- No_1_Civil-Use-ofUAS_Bildschirmversion_sec.pdf (downloaded: 2801 2013)

JOINT AIR POWER COMPETENCE CENTER (2010): Strategic Concept of Employment for Unmanned Aircraft Systems in NATO, http://www.japcc.de/fileadmin/user_upload/projects/ nato_flight_plan_for_uas/NATO_UAS_CONEMP_Final.pdf (downloaded: 0602 2012)

BOTTYÁN Z. (2012): Estimation of in-flight icing characteristics of UAVs during different meteorological conditions, Proc. of the 8th International Conference on Intelligent Unmanned Systems (ICIUS 2012), pp. 418-422.

RIORDAN, D., HANSEN, B. K. (2002): A fuzzy case-based system for weather prediction, Engineering Intelligent Systems, UK, CRL Publishing, pp. 139-146.

HANSEN, B. K. (2007): A Fuzzy Logic-Based Analog Forecasting System for Ceiling and Visibility, Weather and Forecasting, Vol. 22, pp. 1319-1330. https://doi.org/10.1175/2007WAF2006017.1

BOTTYÁN Z., WANTUCH F., TUBA Z., HADOBÁCS K., JÁMBOR K. (2012): Repülésmeteorológiai klímaadatbázis kialakítása az UAV-ok komplex meteorológiai támogató rendszeréhez, (Creation of a new climatic database for aviation meteorological support system of unmanned aerial vehicles), Repüléstudományi Közlemények Vol. 24, Issue

3, pp. 11-18.

MEYER, M. A., BUTTERFIELD, K. B., MURRAY, W. S., SMITH, R. E., BOOKER, J. M. (2002): Guidelines for eliciting expert judgment as probabilities or fuzzy logic, In. Fuzzy Logic and Probability Applications: Bridging the gap, Ross, T. J.-Booker, J. M.-Parkinson, W. J. Eds., Society for Industrial and Applied Mathematics, pp. 105-123. https://doi.org/10.1137/1.9780898718447.ch6

SAATY, T. L. (1977): A scaling method for priorities in hierarchical structures, Journal of Mathematical Psychology, Vol. 15, pp. 234-281. https://doi.org/10.1016/0022-2496(77)90033-5

SAATY, T. L. (1991): Some mathematical concepts of analytic hierarchy process, Behaviormetrika, No. 29, pp. 1-9. https://doi.org/10.2333/bhmk.18.29_1 